\title{
Chronic Suppurative Otitis Media (CSOM): Etiological Agents and Antibiotic Sensitivity Pattern of the Isolates
}

\author{
METRI BASAVARAJ $\mathrm{C}^{1}$ P JYOTHI ${ }^{2}$
}

\begin{abstract}
:
Introduction: Chronic suppurative otitis media (CSOM) remains one of the most common childhood chronic infectious diseases worldwide. It is recognized as an important cause of preventable hearing loss in the developing world. The present study was carried out to determine the etiological agent of CSOM and their antibiotic susceptibility pattern at the teaching hospital in North Karnataka.

Methods: Samples were collected from patients in accordance with standard protocols. Organisms were identified by conventional microbiological techniques. Antibiotic susceptibility of the isolates was done by disc diffusion method according Clinical Laboratory Standards Institute (CLSI) guidelines.

Results: A total of 159 patients were included in the study, out of which $53.5 \%$ were males. Majority of the patients (85//59) were in the age group of I-20 years. Pseudomonas was the most common organism causing CSOM, closely followed by Staphylococcus aureus. Pseudomonas were more sensitive to piperacilln-tazobactam (91\%), followed by amikacin (80\%). Among Staphylococcal isolates sensitivity was more to linezolid (93\%), closely followed by piperacilln -tazobactam (88\%). $73 \%$ of the Gram negative bacilli were sensitive to amikacin and $67 \%$ to gentamicin

Conclusion: Due to the easy availability and widespread use of antibiotics the susceptibility pattern of the pathogenic microorganisms are changing, therefore it is imperative to know the local susceptibility pattern of the causative agents, to treat the infection effectively.
\end{abstract}

Key words: Antimicrobial resistance, Antibiotics, Chronic suppurative otitis media (CSOM).

\section{Introduction:}

Chronic suppurative otitis media (CSOM) remains one of the most common childhood chronic infectious diseases worldwide. ${ }^{1}$ It is recognized as an important cause of preventable hearing loss in the developing world. Its association with hearing impairment, death, and severe disability due to central nervous system involvement and the high cost incurred in its management, make CSOM a significant health problem in developing countries. ${ }^{2}$

Chronic suppurative otitis media (CSOM) is a disease of multiple etiology and is well known for its persistence and recurrence, despite treatment. The microbiological flora of the middle ear varies and depends on the type of otitis media. In the acute form, the major organisms present are Hemophilus influenzae, Streptococcus pneumoniae, Pseudomonas aeruginosa and anerobic bacteria. CSOM has received considerable attention, not only because of its high

1. Associate professor, Department of Microbiology, BLDEU's Shri B M Patil Medical College, Bijapur -Karnataka, India.

2. Assistant professor, Department of Microbiology, BLDEU's Shri B M Patil Medical College, Bijapur -Karnataka, India.

Correspondence: Dr. Metri Basavaraj C, Associate professor, Department of Microbiology, BLDEU's Shri B M Patil Medical College, Bijapur -Karnataka-586103, India. Tel: 91-9964106980, E-mail: basucm@rediffmail.com. incidence and chronicity, but also because of issues such as bacterial resistance and ototoxicity with both topical and systemic antibiotics. ${ }^{3}$ The indiscriminate, haphazard use of antibiotics and poor follow up of the patients have resulted in persistent low grade infectional changes in the microbiology of the disease, the advent of new antimicrobials, anti-inflammatory and anti-histamine agents make an evaluation of bacterial flora of CSOM important. ${ }^{4}$

The study of the micro-organisms commonly associated with CSOM and their in vitro antibiotic sensitivity pattern is very pertinent for the clinician to plan a general outline of treatment for the patient with a chronically discharging ear. ${ }^{5}$ Majority of the patients neglect the disease because of its silent course. Illiteracy and low socio-economic status add to the magnitude. ${ }^{6}$ Several studies have been conducted in India and across the world ${ }^{7-14}$ to know the etiological agent of CSOM and their antibiotic susceptibility pattern. Knowledge of local micro-organism pattern and their antibiotic sensitivity is essential for effective and low cost treatment. ${ }^{15}$ The present study was carried out to determine the etiological agent of CSOM and their antibiotic susceptibility pattern at the teaching hospital in North Karnataka. 


\section{Materials and methods:}

The study was carried out in the Department of Microbiology, in our Medical College, Bijapur, India over a period of 2 years from January 2010 to December 2011. A total of 159 patients with CSOM of all age groups and both sexes attending inpatient department as well as the outpatient departments were selected randomly for the study.

\section{Collection of sample:}

Ear discharge was collected under aseptic precautions with two sterile swabs in clinically diagnosed cases of chronic suppurative otitis media. Excess discharge is mopped out from external auditory canal and it is cleaned with $70 \%$ alcohol first and is allowed to act for 30-40 seconds to achieve sterile area. One was used for Gram staining and other one for aerobic culture. ${ }^{16,17}$

\section{Gram staining:}

With one swab a thin smears was made on a clean greasefree glass slide.The dried and heat-fixed smears were stained by - Gram staining and examined to note various morphological types of bacteria, their number, Gram reaction, presence or absence of inflammatory cells and also to note the numbers of squamous epithelial cells in the sample., ${ }^{5,17}$

\section{Aerobic culture:}

The second swab is used for inoculation on blood agar, nutrient agar and MacConkey agar plates. All plates are incubated aerobically at 37? C and evaluated at 24 hours, 48 hours and 72 hours and the plates are discarded if there is no growth. The specific identification of bacterial pathogens is done by using standard bacteriological methods. ${ }^{18}$

\section{Antimicrobial susceptibility testing:}

Antimicrobial susceptibility test for all isolates were carried out on Mueller Hinton agar plate using Kirby Bauer disc diffusion method. Antibiotic discs were procured from HIMEDIA labs (India). Results were interpreted using Clinical Laboratory Standards Institute (CLSI) guidelines. ${ }^{19}$

\section{Results}

\section{Table-I}

Age and gender wise distribution of the isolates.

\begin{tabular}{lccc}
\hline Parameter & Value & No. of isolates(n=159) & Percentage \\
\hline Sex & Male & 85 & 53.5 \\
& Female & 74 & 46.5 \\
Age group & $1-20$ & 84 & 52.8 \\
& $21-40$ & 53 & 33.3 \\
& $41-60$ & 20 & 12.6 \\
& $>61$ & 02 & 01.3 \\
\hline
\end{tabular}

A total of 159 patients were included in the study, out of which $53.5 \%$ were males. Majority of the patients (85/159) were in the age group of 1-20 years, within this age group more number were (54/85) from below 10 years of age (Table 1$)$.

Table-II

Distribution of bacterial isolates causing CSOM.

\begin{tabular}{lcc}
\hline Organism & No. of isolates & Percentage \\
\hline Pseudomonas spp. & 53 & 33.3 \\
Staphylococcus aureus & 46 & 28.9 \\
Klebsiella spp. & 13 & 08.2 \\
CONS & 12 & 07.6 \\
Proteus spp. & 11 & 06.9 \\
Citrobacter spp. & 11 & 06.9 \\
Fungi & 10 & 06.3 \\
Acinetobacter & 03 & 01.9 \\
\hline Total & 159 & 100 \\
\hline
\end{tabular}

CONS: coagulase negative Staphylococcus.

Pseudomonas was the most common organism causing CSOM, closely followed by Staphylococcus aureus (Table II).

\section{Table-III}

Antibiotic susceptibility of Pseudomonas spp. causing CSOM

\begin{tabular}{ccccccccccc}
\hline G & CF & NF & CB & AX & AK & PT & CFS & OF & NT & I \\
\hline 66 & 68 & 45 & 53 & 10 & 80 & 91 & 72 & 75 & 57 & 92 \\
\hline
\end{tabular}

G: gentamicin, CF: ciprofloxacin, NF: norfloxacin, CB: carbenicillin, AX: amoxicillin-clavulanic acid, AK: amikacin, PT: piperacillin-tazobactam, CFS: cefoperazone-salbactam, OF: ofloxacin, NT: netilmicin, I: imipenem.

Pseudomonas were more sensitive to piperacilln-tazobactam (91\%), followed by amikacin (80\%) and highly resistant to amoxicillin-clavulinic acid (90\%) followed by norfloxacin (55\%) as shown in Table III. Resistance was much higher to amoxicillin-clavulinic acid compared with other antibiotics and the difference is statistically significant $(P<0.05)$.

\section{Tabl-IV}

Antibiotic susceptibility of Staphylococcus spp. causing CSOM

\begin{tabular}{cccccccccccc}
\hline E & T & CE & CX & PT & CFS & G & CF & AX & CU & AZ & LZ \\
\hline 49 & 69 & 36 & 21 & 88 & 79 & 48 & 38 & 33 & 57 & 62 & 93 \\
\hline
\end{tabular}

E: Erythromycin, T: tetracycline, CE: cephalaxin, CX: cloxacillin, PT: pipercillin-tazobactum, CFS: cefoperazone-salbactam, G: gentamicin, CF: ciprofloxacin, AX: amoxicillin-clavulanic acid, CU: cefuroxime, AZ: azithromycin, LZ: linezolid. 
Among Staphylococcal isolates sensitivity was more to linezolid (93\%), closely followed by piperacilln-tazobactam (88\%), and resistant to cloxacillin(79\%) and cephalexin (64\%) as shown in Table 4.

Table-V

Antibiotic susceptibility of Gram negative bacilli causing CSOM

\begin{tabular}{|c|c|c|c|c|c|c|c|c|c|c|}
\hline AX SF & $\mathrm{CU}$ & $\mathrm{T}$ & G & $\mathrm{CO}$ & $\mathrm{CF}$ & $\mathrm{CX}$ & CE & $\mathrm{AK}$ & OF & NT \\
\hline 3 & 25 & 21 & 67 & 31 & 37 & 13 & 10 & 73 & 61 & 63 \\
\hline
\end{tabular}

AX: amoxicillin-clavulanic acid, SF: sparfloxacin, CU: cefuroxime, T: tetracycline, G: gentamicin, CO: co-trimoxazole, CF: ciprofloxacin, CX: cloxacillin, CE: cephalexin, AK: amikacin, OF: ofloxacin, NT: netilmicin.

Seventy three percent of the Gram negative bacilli were sensitive to amikacin, $67 \%$ to gentamicin and $63 \%$ to netilmicin. Resistance among Gram negative bacilli were more against cephalexin (90\%), cloxacillin (87\%) and amoxyclav (85\%).

\section{Discussion}

In CSOM, bacteria can reach the middle ear either from the nasopharynx through the Eustachian tube or from the external ear canal through a non-intact tympanic membrane ${ }^{[1]}$. The sex wise distribution in the present study showed $53.5 \%$ of total cases of CSOM were males and $46.5 \%$ were females. The difference was statistically non significant ( $\mathrm{P}$ value $>$ 0.05 ) Similar results of marginal male preponderance were reported by previous studies. 4,6,14,20

In the present study, highest prevalence (34\%) was reported in the age group of 1-10 years. This findings was in accordance to other literature reports. ${ }^{7,20,21}$ However Vijaya et al. ${ }^{14}$ and Loy et al. ${ }^{15}$ have reported maximum number of patients in second and third decade respectively. The incidence of CSOM peaks in the early childhood before the maturation of immune system. Also due to increased risk of respiratory infection, short and straight eustachian tube in infants and young children allows ready access of bacteria to middle ear and abundance of lymphoid tissue in children may obstruct the eustachian tube in infants and young children allows ready access of bacteria to middle ear. ${ }^{22,23}$

In the current study Pseudomonas spp. (33.3\%) was the most common organism isolated. This finding is in agreement with study conducted by Loy et al. ${ }^{15}$ and Hiremath et al. ${ }^{6}$ who have also reported Pseudomonas spp. as the predominant organism causing CSOM. In various studies conducted across India,4,5,6,15 Staphylococcus aureus was the second most common cause of CSOM, which correlates well with study conducted in this centre where Staphylococcus aureus (28.9\%) was reported as second most common cause of CSOM.

Fungi were isolated in $6.3 \%$ of the total isolates in the current study with Aspergillus spp. being the predominate isolate. Even though fungi are routinely regarded as colonizers, they can be pathogenic in the already inflamed ear. ${ }^{24}$ Though fungi have been isolated in less numbers in our study, they have been isolated in $50 \%$ of the cases of CSOM in previous studies. $^{1}$

It appears as if the era of antibiotics is giving way to an age of anxiety as the emer-gence of antibiotic resistance is becoming more common in man. Being prolific and so unique, bac-teria can replicate a new genera-tion every few minutes but the "generation gap" can sometimes be' as little as 20 minutes. Bacte-ria seem to-inherit this "property” of antibiotic resistance from their predecessors. Human negligence is also responsible for the develop-ment of antibiotic resistance. As soon as symptoms subside many patients stop taking antibiotics be-fore completion of therapy and al-low partially-resistant microbes to flourish. ${ }^{5}$ In the present study piperacilln-tazobactam, amikacin were found to be the most effective antimicrobial agents against Pseudomonas spp. and linezolid, piperacilln-tazobactam and cefoparazone-salbactam were most effective against Staphylococcus spp. Amikacin and gentamicin were most effective against the other gram negative bacilli.

\section{Conclusion:}

Due to the easy availability and widespread use of antibiotics the susceptibility pattern of the pathogenic microorganisms are changing, therefore it is imperative to know the local susceptibility pattern of the causative agents, to treat the infection effectively and as for as possible this knowledge should be used to formulate antibiotic policy.

\section{Conflict of interest: None.}

\section{References}

1. Verhoeff M, van der Veen E L, Rovers M M, Sanders EAM, Schilder A GM. Chronic suppurative otitis media: A review. Int J Pediatr Otorhinolaryngol 2006;70:1-12.

2. Nnebe-Agumadu U, Okike O, Orji I, Ibekwe RC. Childhood suppurative otitis media in Abakaliki: Isolated microbes and in vitro antibiotic sensitivity pattern. Niger J Clin Pract 2011;14:159-62.

3. Malkappa S, Kondapaneni S, Surpam RB, Chakraverti TK. Study of aerobic bacterial isolates and their antibiotic susceptibility pattern in chronic suppurative otitis media. Indian J Otol 2012;18:136-9. 
4. Nandy A, Mully PS, Sivarajan K. Chronic suppurative otitis media - A bacteriological study. Indian J Otol 1991;43: 136-8.

5. Greval RS, Ram S. Bacteriological patterns of chronic suppurative otitis media, in Ludhiana. Indian J Med Sci 1996;50:192-5.

6. Hiremath SL, Kanta RC, Yeshwanathrao M, Vasantha Kumar $\mathrm{CM}$. Aerobic bacterial isolates of CSOM and their antibiotic sensitivity pattern. The Indian Practitioner 2001;54:486-9.

7. Taneja MK. CSOM: A bacteriological study. Indian J Otol 1995;1:24-7.

8. Kuchal V. Antibiotic sensitivity pattern in chronic suppurative otitis media (Tubotympani type) in Kumoun region. Indian J Otol 2010;16:17-21.

9. Goyal R, Aher A, De S, Kumar A. Chronic suppurative otitis media-A clinico microbiological study. Indian J Otol 2009;15:18-22.

10. Kumar S, Sharma R, Saxena AK, Pandey A, Gautam P, Jain R. A study of bacterial flora and sensitivity to antibiotics in cases of CSOM TTD in western UP. Indian J Otol 2008;14:20-4.

11. Chakraborty A, Bhattacharjee A, Purkaystha P. Microbiological profile of chronic suppurative otitis media: Its significance in North-East India. Indian J Otol 2005;11: 39-44.

12. Naheed P, Khan Z, Khan IM, Suhail AS, Zuber A. Bacteriological study of patients with discharging otitis media-A rural study. Indian J Otol 2003;9:29-32.

13. Fatma AA, Assiry S, Siraj MZ. Microbiological evaluation and aspects on management of chronic suppurative otitis media in Riyadh. Indian J Otol 1998;4:115-20.

14. Vijaya D, Nagarathnamma T. Microbiological study of chronic suppurative otitis media. Indian J Otol 1998;4: 172-4.
15. Loy AHC, Tan AL, Lu PKS. Microbiology of chronic suppurative otitis media in Singapore. Singapore Med J 2002;43:296-9.

16. Gupta V, Gupta A, Sivarajan K. Chronic suppurative otitis media;Anaerobic microbiological study. Indian J Otol 1998;4:79-82.

17. Winn WS, Allen SD, Janda WM, Konemam EW, Procop GW, Schreckenberger PC. Charts. In:Darcy P, Pterson N, Montalbano J, editors. Koneman's Color Atlas and Textbook of Diagnostic Microbiology. 6th Ed. Philadelphia: Lippincott; 1997:1442-535.

18. Collee JG, Miles RS. Tests for identification of of Bacteria. In: Collee JG, Fraser AG, Marmion BP, Simmons A, Eds. Mackie and McCartney Practical Medical Microbiology. 14 th ed. New York: Churchill Livingstone; 1996:131-149.

19. Clinical and Laboratory Standard Institute (CLSI): Performance standards for antimicrobial susceptibility testing. $18^{\text {th }}$ International Supplement. CLSI document M 100- 18. Wayne, Pennsylvania; 2008.

20. Rao BN, Reddy MS. Chronic suppurative otitis media - A prospective study. Indian J Otolaryngol Head Neck Surg 1994;3:72-7.

21. Poorey VK, Arati Iyer. Study of bacterial flora in CSOM and its clinical significance. Indian J Otolaryngol Head Neck Surg 2002;54:91-5.

22. Nwabuisi C,Olege FE. Pathogenic agents of chronic suppurative otitis media in Ilorin, Nigeria. East African Med J 2002;79:202-5.

23. Gulati SK. Investigative profile in patients of chronic suppurative otitis media. Indian J Otol 1997;3:59-62.

24. Shashidhar V, Mukhopadhyaya C, Prakash R, Pillai S, Pujary K, Pujary P. Chronic suppurative otitis media: optimizing initial antibiotic therapy in a tertiary care setup. Indian J Otolaryngol Head Neck Surg 2012;64:285-9. 